\title{
Ön Çapraz Bağ Rekonstrüksiyonu Sonrası Operasyonun Fonksiyonel Sonuçlarının Sportif Aktivitelerle iliș̦kisi
}

\section{The Relationship Between Functional Results of Operations After Anterior Cruciate Ligament Reconstruction and Sports Activities}

\author{
Ferdi SARI ${ }^{1}$ (D), Murat ÖZȘAHIN² (D), Nezih ZiROĞLU1 \\ ${ }^{1}$ Beylikdüzü Devlet Hastanesi, Ortopedi ve Travmatoloji Kliniği, İstanbul, Türkiye \\ ${ }^{2}$ Orta Doğu Özel Hastanesi, Ortopedi ve Travmatoloji Kliniği, Adana, Türkiye \\ ORCID ID: Ferdi Sarı 0000-0002-8122-6217, Murat Özşahin 0000-0001-6698-8435, Nezih Ziroğlu 0000-0002-2595-9459
}

Bu makaleye yapılacak atıf: Sarı F ve ark. Ön Çapraz Bağ Rekonstrüksiyonu Sonrası Operasyonun Fonksiyonel Sonuçlarının Sportif Aktivitelerle İlișkisi. Med J West Black Sea. 2021;5(2):188-192.

Sorumlu Yazar

Ferdi Sarı

E-posta

ferdibeylikduzu.md@gmail.com
Öz

Amaç: Bu çalışmada, amatör olarak spor yapan ve ön çapraz bağ (ÖÇB) rekonstrüksiyonu yapılan bireylerde, operasyonun fonksiyonel sonuçları ve sportif aktiviteleriyle olan ilişkisinin araştırılması amaçlandı.

Gereç ve Yöntemler: Ön çapraz rüptürü nedeniyle dört katlı hamstring otogrefti ile artroskopik rekonstrüksiyon uygulanan hastaların fonksiyonel sonuçlarını Lysolm ve Tegner aktivite skorlama sistemi ile retrospektif olarak analiz ettik. Kinezyofobi değerlendirilmesi Tampa ölçeği kullanarak yapıldı.

Bulgular: Çalışmaya dahil olan 61 kişinin tamamı erkekti (yaş dağılım: 17 - 48 yıl, ortalama: 30,6士6,9). Takip süresi en kısa 27 ay iken en uzunu 74 ay olmak üzere ortalama $47.4 \pm 20.5$ ay idi. Ameliyat öncesi

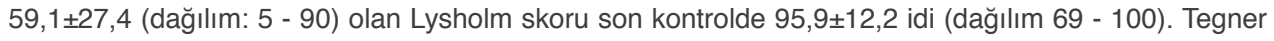
aktivite skorları ortalaması travma öncesi $6,4 \pm 2,8$ (dağılım: $3-10$ ), ameliyat sonrası 5,2 $\pm 3,5$ (dağılım: 3-10) idi. Tampa kinezyofobi ölçeği ortalaması 41,2 $\pm 9,7$ (29-49) olarak bulundu.

Sonuç: Cerrahi sonucunda, hastaların çoğunda fonksiyonel sonuçlar tatmin edici olarak tespit edilirken, yaklaşık yarısında ise aktivite skorları istenilen düzeye ulaşmıştı. Tampa kinezyofobi ölçeği yüksek bulunması, ÖÇB cerrahisinde ne kadar titiz davranılsa da ameliyat öncesinde ve sonrasında alacağı profesyonel fizyoterapi ve psikolojik danışmanlığın da önemli derecede etkili olabileceğini gösterdi.

Anahtar Sözcükler: Kinezyofobi, Lysolm, Rekonstrüksiyon, Ön çapraz bağ

\section{ABSTRACT}

Aim: In this study, it was aimed to investigate the functional results of the operation and its relationship with sportive activities in individuals who do sports amateur and undergo anterior cruciate ligament $(\mathrm{ACL})$ reconstruction.

Material and Methods: We retrospectively analyzed the functional results of patients who underwent arthroscopic reconstruction with a four-layer hamstring autograft due to ACL rupture using Lysolm and Tegner activity scoring system. Kinesiophobia was evaluated using the Tampa scale.

Results: All 61 people included in the study were male (age range: 17 to 48 years, mean: $30.6 \pm 6.9$ ). The duration of follow-up was $47.4 \pm 20.5$ months, with the shortest 27 months and the longest 74 months. The Lysholm score, which was $59.1 \pm 27.4$ (range: 5 to 90 ) preoperatively, was $95.9 \pm 12.2$ at the last control (range 69 to 100 ). Mean Tegner activity scores were $6.4 \pm 2.8$ (range: $3-10$ ) before trauma and $5.2 \pm 3.5$ (range: $3-10$ ) postoperatively. The mean of Tampa kinesophobia scale was found to be $41.2 \pm 9.7(29-49)$. 
Conclusion: As a result of ACL surgery, functional results were found to be satisfactory in most of the patients, while activity scores reached the desired level in approximately half. On the other hand, Tampa kinesophobia scale was found to be high. Therefore, it can be considered that professional physiotherapy and psychological counseling that patients will receive before and after the operation can be significantly effective, even if the ACL surgery is meticulously.

Keywords: Kinesiophobia, Lysolm, Reconstruction, Anterior cruciate ligament

\section{Giriş}

Ön Çapraz Bağ (ÖÇB) dizde en sık yaralanan bağ dokusu olup son yıllarda spor yapan insanların sayısındaki artışa bağlı olarak ÖÇB yaralanma sıklığında artış görülmektedir (1). Bu yaralanmalarda uygulanan cerrahi işlemin kısa dönemdeki en önemli amacı hastanın en kısa sürede en üst düzey aktivite seviyelerine ulaşmasıdır $(2,3)$. Böylece esase hedef oluşabilecek olası posttravmatik artrit tablosunun önüne geçmektir $(4,5)$.

Son dönemde yayımlanan çalışmalarda ÖÇB rekonstrüksiyonu yapılan hastalarda dizde stabilitenin sağlanmış olmasına, düzenli rehabilitasyon programları uygulanmasına ve fonksiyonel skorların düzelmesine rağmen, hastaların hemen hemen yarısının travma öncesi aktivite düzeyine gelmediği belirtilmektedir $(6,7)$. Bu hastalarda kendilerinin hareket korkusu olarak tarif ettiği kinezyofobi, spora dönüşte önemli bir faktördür. Bu korku için ilk defa Kori ve ark. 1990'da "kinezyofobi" terimini kullanmışlardı. Bilimsel çalışmalarda Kinezyofobi son zamanlarda daha fazla ilgi görmektedir ve uyumsuz bilişsel davranışların kısır bir ağıı ve sakatlık döngüsü yaratabileceği varsayılmışıı (8). Kinezyofobi, ameliyat sonrası erken evrelerde normal bir fizyolojik reaksiyon olarak görülebilir, ancak akuttan kronik ağrıya geçiş ve yaralanma yeri ne olursa olsun sağlıkla ilişkili yaşam kalitesi ölçülerinde azalma ile ilişkili olduğu gösterilmiştir (9). İlk olarak bel ağrısında araştııılan, kinezyofobi daha sonra kalça artroplastisinde, ÖÇB rekonstrüksiyonunda ve patellofemoral ağrıda kötü fonksiyonel sonuçlarla ilişkilendirilmiştir (10). Kinezyofobinin çeşitli yaralanmalarda ve prosedürlerde daha kötü sonuçlara yol açtığına dair artan kanıtlarla, tedavi stratejileri dikkat çekmektedir. Fonksiyonel egzersizlerin, izometrik kas egzersizlerinden ve hareket açıkığı egzersizlerinden daha fazla etkinlik sağladığı gösterilmiştir. Psikolojik tedaviler, bir motor fonksiyonun yerine getirildiğini hayal etme dahil olmak üzere hareket korkusunu azaltmayı amaçlayan stratejilere odaklanmıştır $(5,9)$.

Sporcular yaralanma öncesi aktivite düzeyine dönmek istese de, bazı durumlarda, örneğin yeniden yaralanma korkusu gibi sosyal nedenler ya da psikolojik engeller spora geri dönüşlerini etkileyebilir $(2,7)$. Bu çalışmada, amatör olarak spor yapan ve ön çapraz bağ (ÖÇB) rekonstrüksiyonu yapılan bireylerde, operasyonun fonksiyonel sonuçları ve sportif aktiviteleriyle olan ilişkisinin araştııı ması amaçlandı.

\section{GEREÇ ve YÖNTEMLER}

Bu çalışmada, ÖÇB rüptürü nedeniyle artroskopik rekonstrüksiyon uygulanan 61 sportif aktivite yapan genç erişkin hastanın sonuçları retrospektif değerlendirildi. Hastalarımızın 61 'i de erkekti. Yaş dağıımı 18 ile 50 yıl arasında değişmekte olup, ortalaması $54,54 \pm 6,84$ yıldır. Olgularımızın 33'ünün sağ dizi, 28'inin sol diziydi. Hastalarımızı en kısası 27 ay, en uzunu 74 ay olmak üzere ortalama 47,4 ay takip ettik.

\section{Rekontrüksiyon Yaklaşımı ve Takipler}

Hastaların tümü spinal anestezi altında ve turnike kontrolünde opere edildi. Olgulardan 31 tanesine anatomik, 30 tanesine transtibial teknikle, dört katlı otojen hamstring grefti kullanarak ÖÇB rekonstrüksiyonu uygulandı. Tüm hastalarda, basma sırasında daha kontrollü bir ortam sağlamak için, ilk altı hafta açı ayarlı uzun dizlik kullanıldı. Illk üç hafta süre ile yalnızca denge amaçı statik basmaya izin verildi. Önce, hiperekstansiyonu engelleyecek şekilde, 0 derecede ekstansiyon ve 80 derecede fleksiyon açı ayarı ile başlandı. Fleksiyon her hafta 10 derece artırıldı. Beşinci hafta da dahil olmak üzere, fleksiyon 110 derecede tutuldu ve altın$\mathrm{Cl}$ haftada tamamen serbest bırakıldı. Bu süreç boyunca egzersizler yapıldı. Üçüncü ay sonunda düz koşuya, altın$\mathrm{Cl}$ ayda mücadeleli olmayan sporlara izin verildi. Hastalar dokuzuncu ayda tamamen serbest bırakıldı. Fonksiyonel değerlendirmeler, ameliyat öncesinde ve en son geldikleri kontrolde Lysholm skoruna ve Tegner aktivite skoruna göre yapıldı. Hareket korkusu değerleri Tampa kinezyofobi ölçeği ile değerlendirildi.

\section{İstatistiksel Analiz}

Tüm veri analizlerinde SPSS 26.0 programı kullanılırken 0,05 değeri anlamlılık düzeyi olarak kabul edildi. Frekans, ortalama, standart sapma ve medyan gibi tanımlayıcı veriler istatistiksel analiz gerekliliğine göre paylaşılırken tüm verilerde ortalama ve medyan değerler verildi. Hasta verilerinin dağııım analizinde normal dağıım göstermeyen bağımsız değişkenler arasındaki farklılıkları analiz etmek için Mann-Whitney-U testi kullanıldı. Veriler arasındaki bağıntının analizinde ise Spearman korelasyon testi kullanıldı.

\section{BULGULAR}

Hastalarımızın Lysholm skorunda genel olarak artış saptarken; Tegner skorunda düşüş saptadık. Ameliyat öncesi 
Tablo 1: İyileşme Skorlarının Gruplara Göre Değerlendirmesi

\begin{tabular}{ccccccccc}
\hline \multirow{2}{*}{ Değişkenler } & & \multicolumn{2}{c}{ Total } & \multicolumn{2}{c}{ Anatomik } & \multicolumn{2}{c}{ Transtibial } \\
\cline { 2 - 9 } & & $\mathbf{r}$ & $\mathbf{p}$ & $\mathbf{r}$ & $\mathbf{p}$ & $\mathbf{r}$ & $\mathbf{p}$ \\
\hline \multirow{3}{*}{ Lysholm } & Preop & $-0,033$ & 0,803 & 0,004 & 0,982 & $-0,092$ & 0,642 \\
\cline { 2 - 9 } & Postop & $-0,075$ & 0,568 & $-0,048$ & 0,796 & $-0,132$ & 0,503 \\
\cline { 2 - 9 } & Fark & 0,033 & 0,803 & $-0,021$ & 0,909 & 0,085 & 0,667 \\
\hline \multirow{3}{*}{ Tegner } & Preop & $-0,308$ & $\mathbf{0 , 0 1 6}$ & $-0,150$ & 0,421 & $-0,490$ & $\mathbf{0 , 0 0 8}$ \\
\cline { 2 - 9 } & Postop & $-0,270$ & $\mathbf{0 , 0 3 5}$ & $-0,084$ & 0,652 & $-0,528$ & $\mathbf{0 , 0 0 4}$ \\
\cline { 2 - 9 } & Fark & $-0,095$ & 0,468 & $-0,105$ & 0,576 & $-0,151$ & 0,444 \\
\hline
\end{tabular}

Tablo 2: Ameliyat teknikleri (anatomik ve transtibial yaklaşım) ile fonksiyonel sonuçlarının yaş ve takip süresi ile ilişkisi

\begin{tabular}{lccc}
\hline Değişkenler & Min-Maks & Medyan & $\pm \mathbf{s}$ \\
\hline Yaş & $17-48$ & 31 & $30,6 \pm 6,9$ \\
\hline Takip Süresi (Ay) & $10-49$ & 20 & $23,2 \pm 10,9$ \\
\hline Lysholm & & & \\
\hline " Preop & $5-90$ & 62 & $59,4 \pm 15,2$ \\
\hline " Postop & $69-100$ & 100 & $96,7 \pm 6,7$ \\
\hline Tegner & & & \\
\hline " Preop & $3-10$ & 7 & $6,6 \pm 1,3$ \\
\hline " Postop & $3-10$ & 5 & $5,4 \pm 1,6$ \\
\hline
\end{tabular}

59,1 $\pm 27,4$ (dağılım: 5-90) olan Lysholm skoru son kontrolde 95,9 $\pm 12,2$ idi (dağılım 69-100). Tegner aktivite skorları ortalaması travma öncesi 6,4 $\pm 2,8$ (dağılım: 3-10), ameliyat sonrası 5,2 $\pm 3,5$ (dağııı: 3-10) idi. Ameliyat öncesi ve sonrası dönemde, Lysholm skorundaki artış istatistiksel olarak anlamlıdır $(p=0,009)$. Bu değişim anatomik ve transtibial gruplar arasında istatistiksel olarak anlamlı farklılık göstermedi $(p=0,089)$ (Tablo 1).

Ameliyat öncesi ve ameliyat sonrası dönemde, Tegner skorlarında anlamlı bir düşüş vardı $(p=0,012)$. Bu değişim anatomik ve transtibial gruplar arasında istatistiksel olarak anlamlı farklılık göstermiyordu $(p=0,133)$ (Tablo 1). Buna karşın, 30 hastamızın ameliyat sonu Tegner skoru ameliyat öncesi seviyelerine ulaşabilmişti. Tampa kinezyofobi ölçeği ortlaması 41,2ะ9,7 (29-49) olarak bulundu. Ameliyat teknikleri (anatomik ve transtibial yaklaşım) ile fonksiyonel sonuçlarının, yaş ve ameliyat sonu takip süreleri arasında istatistiksel olarak anlamlı ilişki bulunmamaktaydı $(p=0,309)$ (Tablo 2).

\section{TARTIŞMA}

Çalışmamızda, ÖÇB nedeniyle ameliyat edilen hastalarda ameliyat sonrası takiplerde Lysholm fonksiyonel sonuçlarını yüksek olduğunu gördük. Tegner aktivite skorlardaki değişim ise hastaların yarısında tatminkâr bulundu. Bu sonuçların aksine Tampa Kinezyofobi Ölçeği yüksek olarak gözlemledik. Cerrahi neticesinde, sporculardaki fonksiyonel sonuçlar istenilen düzeye ulaşırken, hastaların ameliyat öncesi aktivitelerine dönüşünde gecikme tespit ettik. Çalışma sonuçlarımız beklentimize uygun şekilde operasyondan etkilenmenin yalnızca fiziksel değil aynı zamanda psikolojik de olduğu sonucunu desteklemektedir.

Yapılan araştırmalarda gösterdi ki, rekonstrüksiyon sonrası fonksiyonel ve işlevsel skorlarda iyileşme olmasına rağmen kişilerin spora dönüşü istenilen seviyede olmamaktadır. (10, 11). Picavet ve ark.nın çalışmasında kinezyofobi ve abartılmış ağrı beklentisinin düşük aktivite düzeyleri ile ilişkili olduğu gösterilmiştir (12). Bu çalışmada kullandığımız Lysholm diz skorunun Türkçe geçerliliği ve kültürel adaptasyonu Çelik ve ark. tarafından sağlanmıştır (13). Hastalarımızın tümünde bu skor mükemmel ve iyi olarak bulunmuştur. Bulduğumuz bu sonuç bize ÖçB cerrahisinin hastalar üzerindeki fonksiyonel etkisinin oldukça olumlu olduğunu düşündürmektedir.

ÖÇB rekonstrüksiyonu sonrası rüptür öncesi aktivite seviyesine ulaşamamanın birçok sebebi vardır. En sık görülen sebepler diz fonksiyonundaki yetersizlik ve tekrar yaralanma korkusudur (14). Baltacı ve ark.'ları kemik-patellar tendon-kemik grefti ile rekonstrüksiyon olan ameliyat sonrası 18-24. aydaki hastaların ameliyat öncesi Tegner Aktivite ölçeği değerlerinin sağlıklı kontrol grubu ile benzer olduğunu ancak ameliyat sonrası aktivite değerlerinin istatistiksel anlamlı olarak düşük olduğunu buldu (15). Bizim çalışmamızda, Tegner aktivite skorlardaki değişim hastaların yaklaşık yarısında tatminkâr bulundu. Ameliyat teknikleri (anatomik ve transtibial yaklaşım) ile fonksiyonel sonuçlar arasında istatistiksel olarak anlamlı bir fark bulunmamaktadır. Çalışmamız bu yönden literatür ile uyumluydu.

ÖÇB rekonstrüksiyonu sonrası hastalar ağrıyı provoke etmemek için hareket ve aktiviteden kaçınabilmektedir. Bu, rehabilitasyon sırasında egzersizlerden ve aktivitelerden uzak durmalarına yol açabilmektedir. Profesyonel rehabilitasyon, kas-iskelet sistemi üzerindeki etkisi ve iyileşme süresine ilişkin bilgilendirmeler ile hastanın ağrı korkusundan kaçınması üzerinde etkili olabilir ve Tampa Kinezyofobi Ölçeğinde düşüşe katkıda bulunabilir $(16,17)$. Bu çalışma- 
da, Tampa Kinezyofobi Ölçeği yüksek olarak gözlendi. ÖÇB rekonstrüksiyonu planlanan hastaların, preoperatif veya erken postoperatif dönemde; depresyon, kișilik özellikleri, ağrı skorları gibi durumlar açısından değerlendirilmesinin, spora dönüşü engelleyecek kinezyofobi fenomenini, erken rehabilitasyon dönemlerinde öngörebilmemizi sağlayacağı kanaatindeyiz. Her hasta bu öngörü ve uygun motivasyon ile kinezyofobi fenomenini aşmaya teşvik edilmelidir. Ayrıca preoperatif kişilik özellikleri, emosyonel durumu ÖÇB rekonstrüksiyonu öncesi değerlendirilerek, erken rehabilitasyon döneminden itibaren hastaların spora dönüş motivasyonu güçlendirilmelidir. Bu bağlamda yapılan cerrahinin sonuçları ve hastanın yaşam kalitesi, hem hastayı hem de cerrahı tatmin edebilecek seviyeye ulaşabilir.

Çalışmamızda bazı kısıtıııklar mevcuttu. Hastaların preoperatif aktivite düzeylerini, hastaların bildirimlerine göre değerlendirdik. Ayrıca hastaların operasyon sonrası standart bir fizyoterapi almamış olmaları neticesinde hasta standardizasyonunda eksiklikler meydana geldi. Diğer bir kısıtılık ise hastaların ameliyat öncesi emosyonel durumunun tespit edilememesi idi.

\section{SONUÇ}

Sonuç olarak, ÖÇB cerrahisi sonucunda, fonksiyonel sonuçlar istenilen düzeye ulaşırken, hastaların ameliyat öncesi aktivitelerine dönüşünde gecikme görmekteyiz. Tampa kinezyofobi ölçeğinin yüksek bulunması, ÖçB cerrahisinde ne kadar titiz davranılsa da, hastaların ameliyat öncesi ve sonrasında alacağı fizyoterapinin ve psikolojik danışmanı̆ğın önemli etkiye sahip olduğunu göstermektedir. Ayrıca amatör olarak spor yapan kişilerin ameliyat sonrası, ameliyat öncesindeki düzeyde spor aktivitelerine dönmekte zorlanacakları konusunda bilgilendirilmeleri gerekmektedir.

\section{Teşekkür}

Yok.

\section{Yazar Katkı Beyanı}

Tüm yazarlar eşit katkı sağlamıştır.

\section{Çıkar Çatışması}

Yazarlar herhangi bir çıkar çatışması bildirmemektedir.

\section{Finansal Destek}

Yazarlar bu çalışma için finansal destek almadıklarını beyan etmişlerdir.

\section{Etik Kurul Onayı}

Çalışmamız Bezmialem Vakıf Universitesi Rektörlüğü'ne bağlı Klinik Araştırmalar Etik Kurulu tarafından 27/08/2020 tarih 4231 sayılı yazısı ile onay alınarak yürütülmüştür.

\section{Hakemlik Süreci}

Kör hakemlik süreci sonrası yayınlanmaya uygun bulunmuş ve kabul edilmiştir.

\section{KAYNAKLAR}

1. Fithian DC, Paxton EW, Stone ML, Luetzow WF, Csintalan RP, Phelan D, Daniel DM. Prospective trial of a treatment algorithm for the management of the anterior cruciate ligament-injured knee. Am J Sports Med 2005; 33: 335-346.

2. Rae PJ, Paterson RS. The natural history of meniscal tears in anterior cruciate ligament insufficiency. Am J Sports Med 1993; 21: $672-679$

3. Yuksel HY, Erkan S, Uzun M. The evaluation of intraarticular lesions accompanying ACL ruptures in military personnel who elected not to restrict their daily activities: The effect of age and time from injury. Knee Surg Sports Traumatol Arthrosc 2006; 14: $1139-1147$.

4. Keene GC, Bickerstaff D, Lohmander LS, Ostenberg A, Englund M, Roos H. High prevalence of knee osteoarthritis, pain, and functional limitations in female soccer players twelve years after anterior cruciate ligament injury. Arthritis Rheum 2004; 50: 3145-3152.

5. Biswal S, Hastie T, Andriacchi TP, Bergman GA, Dillingham MF, Lang P. Risk factors for progressive cartilage loss in the knee: A longitudinal magnetic resonance imaging study in fortythree patients. Arthritis Rheum 2002; 46: 2884-2892.

6. Ardern CL, Webster KE, Taylor NF, Feller JA. Return to sport following anterior cruciate ligament reconstruction surgery: A systematic review and meta-analysis of the state of play. $\mathrm{Br} \mathrm{J}$ Sports Med 2011; 45: 596-606.

7. Wiger P, Brandsson S, Kartus J, Eriksson BI, Karlsson J. A comparison of results after arthroscopic anterior cruciate ligament reconstruction in female and male competitive athletes. A two- to five-year follow-up of 429 patients. Scand J Med Sci Sports 1999; 9(5): 290-295.

8. Kori SH, Miller RP, Todd D. Kinesophobia: A new view of chronic pain behaviour. Pain Management 1990; 3: 35-43.

9. Burwinkle T, Robinson JP, Turk DC. Fear of movement: Factor structure of the tampa scale of kinesiophobia in patients with fibromyalgia syndrome. J Painn 2005; 6: 384-391.

10. Ardern CL, Taylor NF, Feller JA, Webster KE. Return-tosport outcomes at 2 to 7 years after anterior cruciate ligament reconstruction surgery. Am J Sports Med 2012;40:41-48.

11. Linschoten NJ, Johnson CA. Arthroscopic debridement of knee joint arthritis: Effect of advancing articular degeneration. J South Orthop Assoc 1997;6:25-36.

12. Picavet HS, Vlaeyen JW, Schouten JS. Pain catastrophizing and kinesiophobia: Predictors of chronic low back pain. Am J Epidemiol 2002;156:1028-1034.

13. Çelik D, Coşkunsu D, Kılıçoğlu Ö. Translation and cultural adaptation of the Turkish Lysholm Knee Scale: Ease of use, validity and reliability. Clin Orthop Relat Res 2013;471(8): 2602-2610.

14. Webster KE, Feller JA, Lambros C. Development and preliminary validation of a scale to measure the psychological impact of returning to sport following anterior cruciate ligament reconstruction surgery. Phys Ther Sport 2008;9(1):9-15. 
Sarı F ve ark.

15. Baltacı G, Yılmaz G, Atay AÖ. The outcomes of anterior cruciate ligament reconstructed and rehabilitated knees versus healthy knees: A functional comparison. Acta Orthop Traumatol Turc 2012; 46(3):186-195.

16. Tichonova A, Rimdeikienè I, Petruševičienè D, Lendraitienè $E$. The relationship between pain catastrophizing, kinesiophobia and subjective knee function during rehabilitation following anterior cruciate ligament reconstruction and meniscectomy: A pilot study. Medicina 2016; 52: 229-237.
17. Han JK, Chun KC, Lee SI, Kim S, Chun CH. Comparison of modified transtibial and anteromedial portal techniques in anatomic single-bundle ACL reconstruction. Orthopedics 2019; 42(2): 83-89. 